\title{
GELENEKSEL TÜRK TIYATROSUNUN ULUSAL TIYATROMUZA KAYNAKLIĞI ÜZERINDE YENIDEN DURMAK
}

A raștırmacılarımızın ve yazarlarımızın bir bölümünün tiyatromuzda "özümüzü bulma" amacıyla yalnızca Geleneksel Halk Tiyatrosunu kaynak görmelerini yeniden ele almak istiyorum. Eğer bir kimlik arayıșında isek ve ulusal kimliğimizi yansıtacak bir tiyatro yaratmak peșindeysek koca Türk tarihinin ve devletlerinin içinde Osmanlı İmparatorluğu'nun çöküș yıllarındaki bașkentinin eğlence tarihini olușturan Geleneksel Halk Tiyatrosu adı altında toplanan Karagöz ve Ortaoyunu türlerini model almak kanımca hem eksik hem de yanlıștır.

Türk sanatı üzerindeki araștırmalarıyla tanınmıș Mimar Doğan Kuban'ın ve rahmetli Hocamız Prof. Dr. Metin And'ın kitaplarından yaptığım alıntılarla savımı desteklemek istiyorum.

Doğan Kuban, bir halkın geleneksel teknikleri kullandığı sürece zaten milli olan bir yaratıcılık içinde olduğuna ișaret eder. Yeni bir milli sanat anlayıșının dile getirilmesi "milliliği” halk için değil sanat kültürünün üst katları için istemek anlamına gelmektedir. Aydınlar sınıfının yarattığı sanat, geçmișin yeni bir perspektif içinde ele alınmasından esinlenirse, bu geriye bakıș, "geriye baktığı için milli” olma vasfını kazanmaz. Çünkü tarihsel veriler sanat eserinin meydana gelișini etkileyen ekonomik, teknik ve kültürel koșulların sadece bir bölümüdür. Milli sanatı biçimsel benzerliklerin tarihsel sürekliliği olarak ele almak bilimsel olmayan bir yorumdur. Biçimlere milli sıfatını verdiren șey, onları doğuran çevre koșullarının doğru ifadesi olmalarında bulunur.

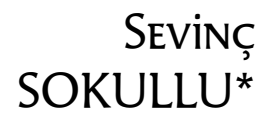

* Prof. Dr. 
Doğan Kuban'a göre, yerleșmiș kültürlere özgü tarih düșüncesinin geliștirdiği toprağa bağlı statik tarih yorumu, genel Türk tarihinin yorumu için yetersiz kalır. Biz kendi tarihimizi yazarken, onun dinamik niteliğini düșünerek, bașkalarında bulamayacağımız yeni yorum ve açıklama modelleri geliștirmek zorundayız.

Kuban'a göre araștırmacılar ve uygulayıcılar Türk kültür ve sanatının dört belirleyicisini dikkate almalıdırlar. Bunlar, 1. Orta Asya Türk toplumlarının kültürü, 2. İslamiyet'in kabulünden sonraki kazanımlar, 3. Yeni yurt Anadolu'daki eski uygarlıkların mirası, 4. Akdenizlilik.

İslam öncesi Türk adını verdiğimiz toplumların katıldıkları iki sanat dünyası vardır: Biri göçerlerin diğeri Orta Asya'nın büyük doğu batı yolları boyunca gelișmiș olan yerleșim merkezlerinin sanatıdır.

Kuban, göçerlerin sanatında step dünyalarına egemen olmuș Türklerin rolünün önemsiz sayılamayacağını vurgular. Türklerin diğer Ortadoğulular ve İranlılarla birlikte Orta Asya kültürünün sahipleri ve tașıyıcıları olduğunu da ilave eder. Bu kültürün, doğudan batıya İslam dünyasına geçișinde birinci derecede rol oynadığını da tartıșımayacak bir gerçek olarak kabul eder. Anadolu'yu Türkleștirenlerin toplumsal kaynağı ise kentlerden çok kırlar, göçebe topluluklardır. Bu açıdan ulusal geleneklerin tașıyıcısı, Anadolu'da kentlerin kozmopolit kültürü dıșında kalan göçebe sanatıdır. Selçuklu çağında ise Anadolu, kültürel bir bütünlüğü barındıramamıștır.

İslamiyet, Türk-Anadolu sentezinde en güçlü, fakat statik karakterli bir etken olmuștur. Yıldırım-Timur'un Ankara Savașlarından hemen sonra Anadolu'nun yeniden bir tek politik yönetim altına girmesi ancak Fatih döneminde olanaklașmıștır. Bundan dolayı, daha önceki ortamda homojen bir kültürden söz edilmesi beklenemez. Yine de Osmanlılarda Anadolu ve Rumeli Türklerinin kendine özgü İslamiyet yorumları vardır.Ancak bütün Osmanlı tarihi boyunca üst tabaka kültürü ve sanatı, geniș yığınlara götü- 
rülememiș ya da benimsetilememiștir. Böylece köklerinden beslenme olanaklarının zayıflığı, üst tabaka kültür ve sanatını, İran ve Arap Ortaçağ kültürü ile yetinmeye yöneltmiștir. Diğer yandan halk kültür ve sanatı, - maddi koșulları sınırlı olduğundan- olanakları geliștirememiș ve çapı sınırlı bir çember içinde kalmıștır. Doğan Kuban, Osmanlı döneminde bu iki kültür ve sanatın yan yana yașadıklarını fakat birbirlerini etkileyerek olușabilecek daha yaratıcı ve evrensel nitelikte bir toplum kültürünün birçok düzeyde olușmadığına dikkat çekmiștir.

Özellikle Geleneksel Türk Tiyatrosu üzerindeki araștırmalarıyla temayüz etmiș rahmetli Hoca'mı Prof. Dr. Metin And da Türk tiyatrosunu dört kesimde inceleyerek bu ilișkisizliğe dikkat çekmiștir. Bunlar, 1. Kırsal kesimdeki köylü seyirlik oyunları geleneği, 2. Kentlerdeki meddah, kukla, Karagöz ve Ortaoyunlarını içeren halk tiyatrosu geleneği, 4. On dokuzuncu yüzyılda Batı etkisiyle bașlayan ve Cumhuriyet'imizle devam eden Türk tiyatrosu geleneğimizdir. Profesör And, köylü tiyatrosu geleneği içinde Türklerin Orta Asya'daki yurtlarından getirdikleri inançların kalıntıları yanında, Anadolu'da Türklerden önce yașamıș toplumların miraslarına da dikkat çeker. Zamanla Köy Seyirlik oyunlarının gerçek amaçlarının unutulmuș olmasına rağmen Türk köylüsünün bu kazanımları büyük kıskançlık ve titizlikle saklamış olmalarını And minnet ve șükranla anmıștır. Bununla birlikte bu geleneğin diğer üç tiyatro geleneğimizle yakınlık ve benzerlik içinde olmayıșına da ișaret etmiștir.

Özetle her iki değerli araștırmacı ayrı alanlardaki incelemelerinin sonucunda birleșmișlerdir. Bin yıllık Anadolu Türk devletlerinde köylü kültürü ve sanatı ile kentlerin çeșitli sanat ve kültürleri yan yana yașamıș fakat bir bütünlüğe ve senteze gitmemiștir. Sanat tarihi açısından bu görüntü Anadolu'da ortak bir sanat üslubunun ortaya çıkmasının zor olduğunun bir ifadesi olmuștur.

Batılı biçimler ise II. Ahmet döneminde Osmanlıların sanat anlayıșına sızmaya bașlamıștır. On dokuzuncu yüzyılda Batııılașma akımı, eskimiș imparatorluk yapı ve kurumlarında "düzenleme"ye giderken Batı tiyatrosu da sahnesi, oyun yeri-seyir yeri ilișkisi ve 
dram türleriyle temașa hayatımızı değișmeye zorlamıștı. Ortaoyunumuz da batıdan esen bu rüzgarla kendini Tuluat Sahnesinde bulmuștur. Kanımca Batıda tiyatronun gerçek ișlevini yitirdiği ve yalnızca yorgun kentsoylunun eğlencesi olmasına izin verildiği bu dönem tiyatrosunu örnek almakla yeni tomurcuklanacak Cumhuriyet tiyatrosu pek kazançlı çıkmamıștır. Bu durum iki yüz elli yıl önceki Alman tiyatrosunda yașanmıștı: Aydınların Latince, soyluların Fransızca konuștuğu Almanya'da bir estetik profesörü bir oyuncu topluluğu ile anlașıyor ve köylü diliyle oynanan doğaçlamalı ve Hans Wurstlu oyunların yerine seyircinin önüne Fransızca'dan çevirdiği Corneille ve Racine oyunlarını getiriyordu. Bir kușak sonraki tiyatro adamlarından Lessing, Gottscheld'in tiyatroda yaptığı reformu șu biçimde eleștiriyordu: "Bu oyunlarla kendi kimliğimizi yansıtan tiyatroyu yaratamayız. Bu neo-klasik oyunlar Fransız kimliğini bile dile getirememișlerdir; onlar Paris ve Saray odaklıdırlar."

Gerçekten bizde de bu özentiye karșı çıkacaklar oldu. Ahmet Kutsi Tecer'in Köșebașı oyunu ile bașlayarak değerli oyun yazarlarımızın bir kesimi eski temașa geleneğimizden esinlenen ve seyirciye çok sıcak gelen oyunlar yazdılar. Fakat öz tiyatromuza giden yol, oyun yer düzeni ve oyunculuğu ile Ortaoyunu ile sınırlı kaldı. Kanımca geleneklerimizden yararlanmak düșüncesi tek açılı bu arayıș yüzünden kendi özümüzü bulma ve yaratma yollarını tıkamıștır.

Öncelikle Ortaoyunu özelliklerinin çoğunun dünyadaki tüm ulusların halk tiyatrolarının ortak özelliği olduğunu bilmemiz gerekir. Bunlar göstermeci üslup, açık uçlu oyun ve kaba komiklik gibi özelliklerdir.

Ortaoyununun oynandığı palanga adı verilen oyun yeri, yani seyircinin dört yanını çevirdiği oyun yeri özellikle bizim kentsel yașam düzeninin yabancısı olan meydanlar olup bunlar Ortaçağ dinsel tiyatrosunun İngiliz Pageant'lerinin, İspanya'da Carroların katılımıyla gerçekleștirilen Corpus Christi törenlerinin, Fransız panayır Farslarının ve İtalyan Commedia dell'Arte temsillerinin tipik oyun 
yerleridir. Doğan Kuban'a göre “Türk șehri, anıtların yoğunlașması bir yana bırakılacak olursa çok büyümüș kırsal yerleșme niteliğindedir. Șehrin içinde genellikle meydanlar bulunmaz"

Gelelim Ortaoyunlarının oyuculuk üslubuna ve anlayıșına: Burada araștırmamızı derinleștirdiğimiz zaman șu bilgilere ulașıyoruz.

Metin And Geleneksel Türk Tiyatrosu kitabında kaynak göstermeyen bir yazının Ortaoyunu bașlangıcı için II. Mustafa'nın saltanat dönemini gösterdiğini, fakat bu temașa türünün II. Mahmut (1812-1830) çağında kesin biçimini aldığını yazar. Ortaoyununun hangi kesimlerde seyredildiğini belirten de ilginç bir alıntıyı kaydeder. Ali Rıza Bey'in verdiği örneğe göre Ortaoyununda siyasal tașlamalar da yapılıyormuș. Lütfen bu siyasal tașlamanın hangi amaçla yapılmıș olduğuna dikkat edelim.

Ali Rıza Bey’e göre Sultan Aziz ünlenmiș Ortaoyuncularını Mızıka-i Hümayun'a almıștı. Bunları milletin ahlakına hizmet edecek yolda tanzim ve ıslah etmek arzusunda olduğu rivayeti varmıș. Fakat bașka kaynaklara göre "mabeyn kâtiplerinden nüdemanın teșvikiyle Ali, Fuat ve Mısırı Kamil Pașalar ve sair vükeladaki evza ve etvarının taklidini yaptırıp eğlendiği” söylenirmiș. Devlet hükümdarlarını vükelayı taklitle eğlendirdikleri cihetle bu gibi eğlencelerin doğru olmadığı da söylenir olduğunu Ali Rıza Bey ekliyor.

Ortaya șu gerçek çıkıyor: Ortaoyunlarının siyasal tașlamaları belli bir ayrıcalıklı kesime hoș görünmeyi amaç edinen ișlevle sınırlı kalmıștır ve bir eğlenceden öteye gitmeyen bir misyon yüklenmiș gibidir. Oysa tiyatronun eğlenceden farkı bir kesimin değil kamunun vicdanını yansıtmasıdır. Yirmi beș yüz yıldır hala geçerli olması için savaștığımız tiyatro temsilleri sinema, televizyon, müzikhol eğlencelerinden farklı olan bir eğlence sunar. Bu haz ve keyif; ülkesinin entelektüel yașamının merkezinde yer alan ve dünyaya bakıșını açıkça ifade eden bir tiyatronun yarattığı aydınlanmanın, tiyatro estetiğiyle birleșmesinden doğar. Gelelim Orta- 
oyunun oyunculuğuna ve oyunu sunumuna. Temsil, çalgıcılar ve Pișekâr'ın palangaya girișiyle bașlar. Pișekâr arkasında Kavuklu olarak neredeyse iki büklüm palangayı dolanırken çalgıcılara seslenir. Bahçe oyunundan:

Pișekâr: (zurna havası eșliğinde gelir ve dört tarafı selamlar) Amma benim pehlivan'ım.

Zurnacl: Buyurun benim pehlivan'ım.

Pișekâr: Bahçe oyununun taklidini aldım, çal da oyunumuz bașlasın; tenezzülen teșrif buyuran hazirun efendilerimiz de zevk-i yap olsunlar.

\section{Büyücü Hoca'dan:}

Pișekâr: $\quad$ Büyücü Hoca'nın taklidini aldım, çal da oyunumuz bașlasın; tenezzülen teșrif buyuran hazirun efendilerimiz de zevk-i yap olsunlar.

Yirminci yüzyılın değerli tiyatro adamlarından Eugenio Barba, Jerzy Grotowski tiyatronun "seyirci sanatı" olduğunu söylerler. Fakat seyirciyi yüceltmekle seyirciye yaltaklık etmek çok farklıdır. Seyirci-oyuncu ilișkisi efendi -ușak ilișkisi değildir ne de bunun tam tersi. Hatta ev sahibi-misafir ilișkisi bile değildir. Bunda bile bir uzaklık, bir denge bozukluğu vardır. Oysa temsile gelen seyirci, ev sahibi gibi temsilin sorumluluğunu paylașır. Oyuncu müziğin melodisini oluștururken, seyirci bas sesleri basarak ona eșlik eder.

Fakat tiyatroyu bir sanat dalı olarak değil de gösteri dünyasının bir parçası olarak ele alan anlayıș, seyirciyi ya görmezden gelecek ya da seyircisini eğlendirmek için maskara olmayı kabul edecektir.

Özetle söylemek istediğim, oyunculuk tavrı ve tiyatro anlayıșı bakımından Ortaoyunu oyunculuk tarzı ve temsil anlayıșını șimdiki 
tiyatromuza örnek almak hatalı bir çaba olmaktadır. Diğer taraf-

tan acaba Ortaoyununun biçimsel özelliklerinden benimseyeceğimiz öğeler bulabilir miyiz? Evet, Ortaoyununun Giriș, Arzbar ve Tekerleme'den olușan Muhavere, Fasıl ve Bitiș bölümlerinden bazıları halkımızın ortak özelliklerini ve tercihlerini yansıtabilir.

Sözgelimi, Tekerleme bölümü bizim ilginç özelliklerimizi yansıtabilir. Bu bölümde Kavuklu Pișekâr'a düșünü bașından geçen gerçek bir olaymış gibi anlatır. Bir öyküsünde sözgelimi bașından geçen türlü olaylardan sonra koca bir lahananın içine düșmüștür. Pișekâr öykünün gelișimini heyecanla dinlerken sonunda Kavuklu'nun yatağından düșüp rüyasından uyandığını öğrenince heyecanı bozuma uğrar. Aynı bozum bir bașka oyunda Laz'ın diğer oyun tiplerinin ve Kavuklu'nun söyleșilerine firsat vermeyen çalçeneliğinde yașanır. Kendisine konușma fırsatı verilmeyen oyuncu "Yahu bu oyunda benim de anlatacaklarım var, madem ki konușamıyorum ben de oynamıyorum" diyerek oyun yerini terk edip seyirci arasına karıșır. Benim seyrettiğim Kanlı Nigâr oyununda Münir Özkul, Laz'ın ağzından laf kapıp konușamadığında sahneden inip seyirci arasına karıșmıș ve bu protesto müthiș bir alkıșla onaylanmıștı.

Kanımca Ortaoyunun özgün estetiğini bu düșle gerçek, oyun gerçeği ile yașam gerçeği arasındaki gidip gelmeler olușturuyor. Bu özellikleri bașarıyla kullanan oyun yazarlarımızdan ilk aklıma geleni değerli yazarımız ve Hocamız Turgut Özakman oluyor.

Bu konudaki düșüncelerimi Karagöz oyunlarına değinmeden bitiremeyeceğim.

Karagöz oyunları köken olarak Güney Doğu Asya gölge oyunlarına bağlanır. Fakat konu, kiși ve tavır olarak Osmanlı yașamının ve daha çok Osmanlı bașkentinin özellikle onyedinci yüzyıl sonraki yașamının bazı kesimlerini yansıtır. Tarihçilere göre tımar, has, zeamet toprak düzeninin bozulmasından sonra daha yoksullașan ya da yașam biçimi aksayan İmparatorluğun dört bir yanından iș aramaya gelenler İstanbullu doldurur. Gerçekten 
Küșteri meydanında Hacivat'la karșılașan Laz Kayıkçı, Rumelili Pehlivan, Acem Halıcı, Arap kahveci Kastamonulu Oduncu iș peșindedirler.

Karagöz oyunları bir perde gazeliyle bașlar. Bu dizelerde Karagöz perdesinin bir ibret perdesi olduğuna ișaret vardır. Bu tasavvufi belirtme oyundaki Karagöz'ün utanmaz söyleșilerine rağmen Karagöz oyununun Ortaoyunundan daha ciddi bir yönü alttan alta tașıdığını gösterir. Șimdi elimizde olmayan metinlerdeki siyasal tașlamaların Sultan Abdülaziz'in yasaklamasından sonra kesildiğini And'ın araștırmaları bize açıklar.

Karagöz gölge oyunu dilinin kabalığı ve açık saçıklığı nedeniyle çok suçlanmıștır. Oysa yüzeydeki delidolu bir zevzeklik gibi görünen bu söyleșiler İmparatorluk bașkentinin çöküșündeki yoksul, yazgısına terkedilmiș insanın çaresizliğini, Hacivatların, Çelebilerin keyif dünyasıyla olan çelișkilerini yansıtır. Bir çok oyunların söyleșileri bu çelișkiler üzerine kurulmuștur. Birkaç örnek Kanlı Nigâr'dan:

\begin{tabular}{|c|c|}
\hline Hacivat: & $\begin{array}{l}\text { Cam-ı meyden vazgeçtim nuș etme } \\
\text { sahbâyı! }\end{array}$ \\
\hline Karagöz: & $\begin{array}{l}\text { Bizim oğlan fundadan gelirken kay- } \\
\text { betmiștir sıpayı! }\end{array}$ \\
\hline Hacivat: & $\begin{array}{l}\text { Bir șıvekârın meftunuyum pek çoktur } \\
\text { âșıklarıI!! }\end{array}$ \\
\hline Karagöz & $\begin{array}{l}\text { Geçen akșam fare götürmüș raftak } \\
\text { kașıkları!! }\end{array}$ \\
\hline
\end{tabular}

Yazıcı'dan hanımla karșılıklı konușma:

II. Hanım: Șemim-i kâkülün beyhude hıfzeyler sabâ sanma/ Meșâm-ı âsuvân-ı desti Çin-e armağan saklar

Karagöz: $\quad$ Sucuğu peyniri sıçan așırmasın diye her gün / Dolabın arkasında iki yaylı bir kapan saklar! 
Dersaadet'in karnı tok sırtı pek bir kesimi vaktini așk șiirleriyle geçirirken Karagözlerin evlerinde fareler bile kemirecek ekmek kırıntısı bulamadıklarından boș raflardaki tahta kașıkları yürütürler.

Orhan Veli'nin Ciğercinin Kedisi'ni Yaprak dergisinde okuduğum zaman bu acı kinayelerin Cumhuriyet döneminde bile geçerliğini koruduğunu șu dizelerinden anlamıștım:

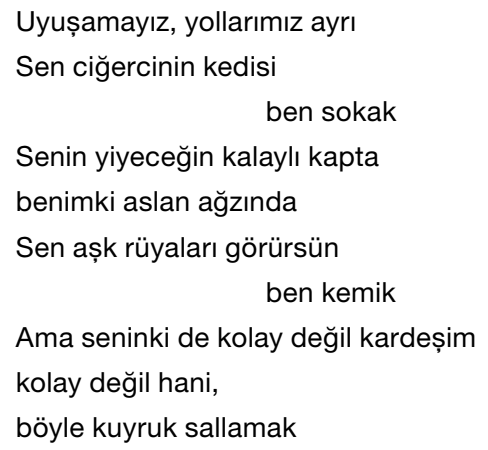

Tanrının günü.

Özetle bizim sesimizi, kimliğimizi temsil edecek bir Türk tiyatrosu sentezi için çeșitli seyirlik geleneklerimizden yalnızca birisine sarımak eksik ve yetersiz kalacaktır. Özellikle Ortaoyununun biçimlerinin yalnız bize ya da Doğu'ya özgü olduğunu düșünmek de yanlıștır.

Daha önce sözünü ettiğim gibi bütün halk geleneklerinde açık biçim, kaba komik ve göstermeci öğeler ortaktır. Diğer yandan Ortaoyununun oyunculuk tavrını ülkemizin tüm halkının karakteristiği sanmak yanlıșın da yanlıșıdır. -En azından Batıdaki zeybeklerin ve efelerin, Doğudaki dadașların danslarını dikkate almak zorundayız.-

Ulusal kimliğimizi topraklarımızın tümünde yașayan halkımızın törelerinde, geleneklerinde, dokuduklardaki kilimlerin nakıșla- 
SEVINÇ SOKULLU

rında, söyledikleri türkülerini, masallarını, törenlerindeki oyun ve adetlerini hesaba katmadan tiyatromuzun yalnız edebiyatını değil sahnesini, dekorunu, yönetmenliğini șekillendirmek mümkün olmayacaktır.

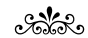

